\title{
SENSITIVITY ANALYSIS OF PRECIPITATION AND RUNOFF PARAMETER TO ASSESS NEMO/INDO12 MODEL OUTPUT
}

\author{
Bayu Priyono ${ }^{a},{ }^{*}$ and Dessy Berlianty ${ }^{a}$ \\ Institute for Marine Research and Observation \\ Jl. Baru Perancak Negara, Jembrana-BALI, Indonesia \\ *Corresponding author: bayu.priyono@kkp.go.id
}

\begin{abstract}
We investigate the sensitivity of precipitation and runoff parameters to a set of NEMO/INDO12 scenarios. A series of simulations are imposed based on reduction rate of each precipitation and runoff parameter to examine its influences to the main ocean characteristics behavior (temperature and salinity). One-set evaluates of two different simulations by using normal and reduce precipitation rate on whole domain Indonesian Sea Water, and the other-set evaluates of two simulations which focusing the experiment by reduce precipitation and runoff rate only on South China Sea region. Our results elucidate the complexity of the relationship between the varied of precipitation and runoff reduction rate, showing that the control of precipitation and runoff rate produced significant impacts on salinity profile up to subsurface stratification. Additionally, the reduction rate of precipitation and runoff indicated that the temperature changes do not always response significantly.
\end{abstract}

Keywords: NEMO/INDO12, precipitation, runoff, sensitivity analysis

\section{INTRODUCTION}

Sensitivity analysis (SA) has been widely used to screen out a small number of sensitive parameters for model outputs from all adjustable parameters [1] in ocean models, helping to improve model predictions by tuning the parameters. However, ocean models have not been thoroughly evaluated to correctly forecast [2].

Several recent studies [3-8] have suggested that performing a SA is an effective way to identify those having the most significant impact on the model behavior. SA investigates how the variation in the output of a numerical model can be attributed to variations of its input's factors [4].

This study systematically explores the sensitivity of the precipitation and runoff reduction rate. The aim of this paper is to investigate the sensitivity of precipitation and runoff parameters to a set of NEMO [9]/INDO12 scenarios. We have used a series simulation to examine any influences to the main ocean characteristics behavior (temperature and salinity). Here to simplify the analysis, the sensitivity analysis is performed to the three-dimensional model applied to operational system, the INDO12, where
INDO12 was previously validated through the Indonesian Archipelago [10], at Makassar Strait [11], Karimata and Gaspar Strait [12].

\section{METHOD}

The configuration of INDO12 ocean model in the frame of Infrastructure Development for Space Oceanography (INDESO) was used in this study. INDO12, a $1 / 12$ regional version of the NEMO physical ocean model covering the whole Indonesian exclusive economic zone (EEZ) has been developed in a fully operational mode [10].

To obtain more understanding the effect of precipitation in the INDO12 model, one-set of two different simulations have been performed. The first simulation run uses a normal precipitation rate, the same used in operational run. The second simulation run uses a rate of $60 \%$ operational run precipitation. Precipitation reduction is applied for entire model domain at every time step in the second simulation. Both simulations use same initial conditions, those are the operational conditions on the $1^{\text {st }}$ January 2013. The simulation is performed for one year $(12 \mathrm{x}$ 30 days) starting on $2^{\text {nd }}$ January 2013. The only changes concern the precipitation rates. 
Five locations have been chosen as demonstration areas to show time series discrepancy of Sea Surface Salinity (SSS) and Sea Surface Temperature (SST). These areas are selected to represent different waters, i.e. Pacific Ocean, internal Indonesian seas, and Indian Ocean. Figure 1 shows selected areas which are used to show the SSS and SST differences.

Other-set of two simulations were done in order to understand the effect of precipitation reduction or runoff reduction on the salinity in the model. The $40 \%$ reduction of precipitation is applied in the first simulation and the $40 \%$ reduction of runoff is applied in the second simulation. Both of them were applied in the same area, i.e. from $2^{\circ} \mathrm{S}-25^{\circ} \mathrm{N}$ and $100^{\circ}-120^{\circ} \mathrm{E}$ (shaded area in Figure 2). These simulations have duration of seven months ( 7 × 30 days) from $2^{\text {nd }}$ January 2013. Both simulations use the same initial conditions, those are the operational conditions from the $1^{\text {st }}$ January 2013. The operational model output is used as a reference of the salinity changes.

Three locations have been chosen to show the salinity changes, i.e. in the South China Sea area, Karimata Strait area, and Java Sea area. The chosen areas were represented by the red square, the blue square, and the magenta square respectively in Figure 2.

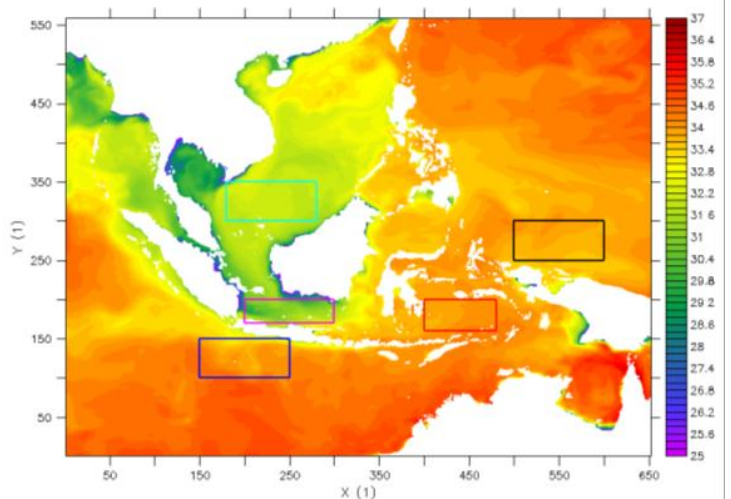

Figure 1. Selected areas are used to show the SSS and SST differences. Black box is the Northern Papua waters represents Pacific Ocean area, the light-blue box represents South China Sea, magenta box represents the Java Sea, red box represents the Banda Sea, and dark-blue box is the Southern Java Sea represents the Indian Ocean area. Shade color shows the sea surface salinity during January 2013 from the operational model.

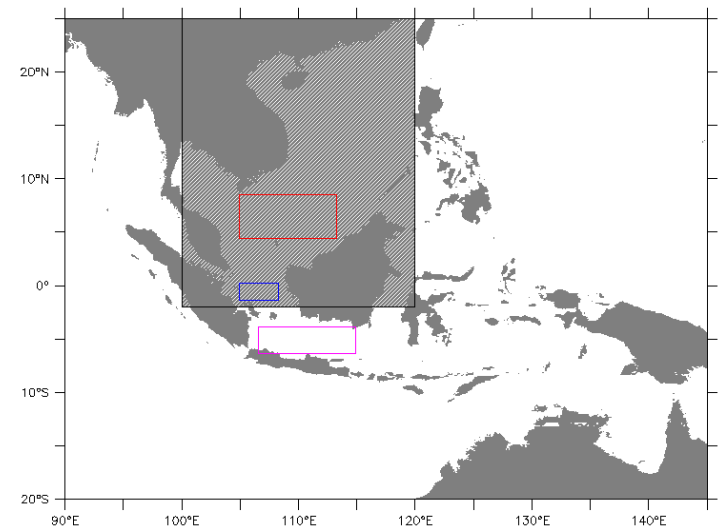

Figure 2. The area where the reduction of precipitation or runoff is applied (shaded area). The red box, the blue box, and the magenta box shows the selected areas that are represent the

South China Sea area, Karimata Strait area, and Java Sea area respectively.

\section{RESULT AND DISCUSSION}

\section{Effect on SSS and SST}

Overlaid time series plots on different areas are shown for precipitation, SSS and SST. See Figure 3 to Figure 7.

In the beginning of the simulation, averaged SSS does not much differ between the two simulations. It is because we are using the same initial conditions. In the Northern Papua (Figure 3) and South China Sea area (Figure 4) the SSS discrepancy is effective after three months. The SSS difference does not vary too much from April to December, probably that the initial condition no longer influences after three months of simulation. Annual average of SSS in the Northern Papua area for operational run and $60 \%$ precipitation are $33.79 \pm 0.22$ psu and $34.16 \pm 0.13$ psu respectively (see detail in Table 1). There is a difference of $0.37 \pm 0.20$ psu between of them. In the South China Sea area, annual average of SSS for both simulations are $31.79 \pm 0.27 \mathrm{psu}$ and $32.15 \pm 0.15$ psu with a lower salinity for the operational run simulation. The annual difference of salinity in this area is $0.36 \pm 0.19$ psu. 

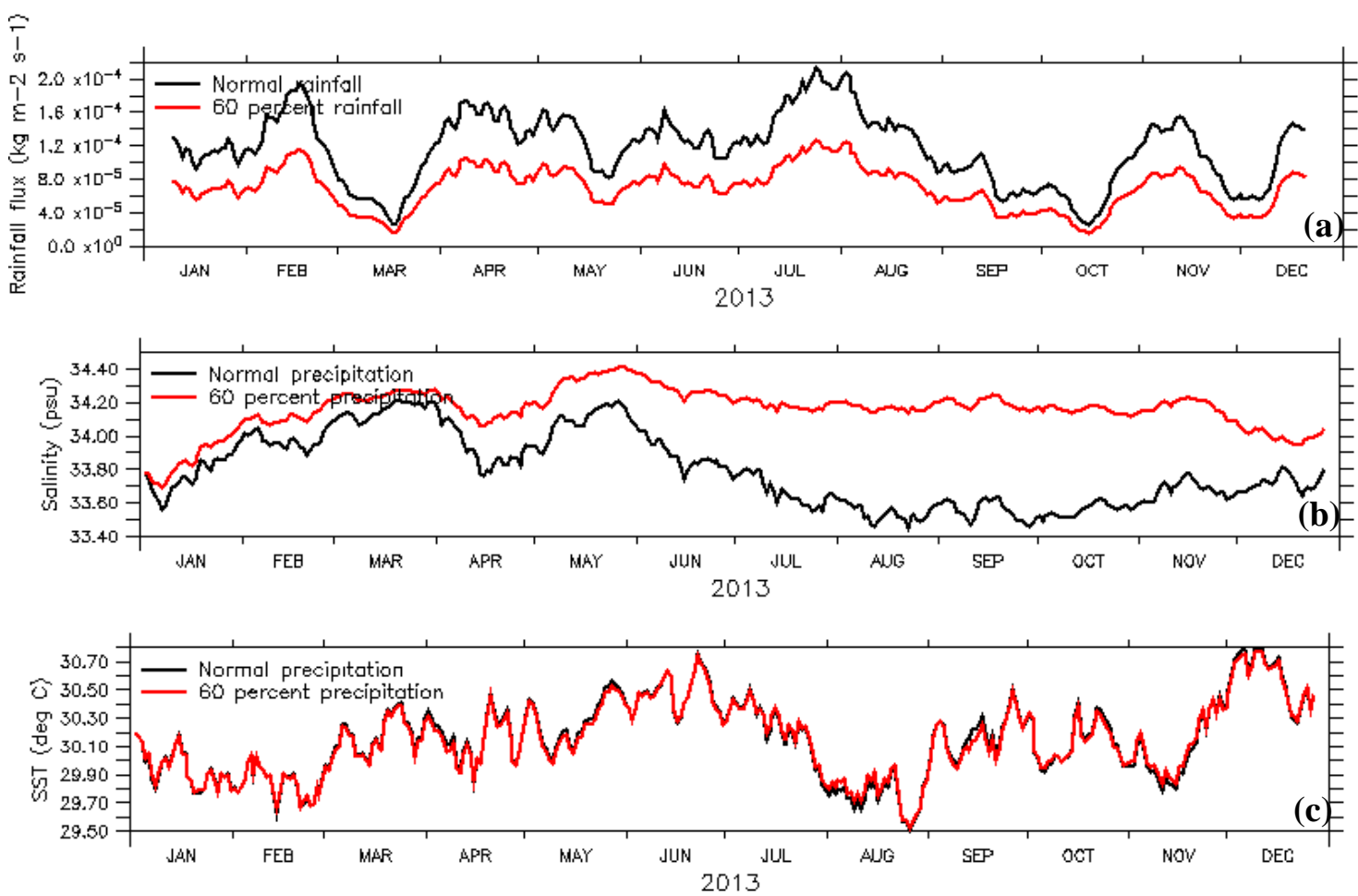

Figure 3. (a) Averaged of 15-day run-mean precipitation, (b) daily sea surface salinity, and (c) daily sea surface temperature on the Northern Papua area. Black line indicates normal precipitation and red line indicates $60 \%$ precipitation simulated model.
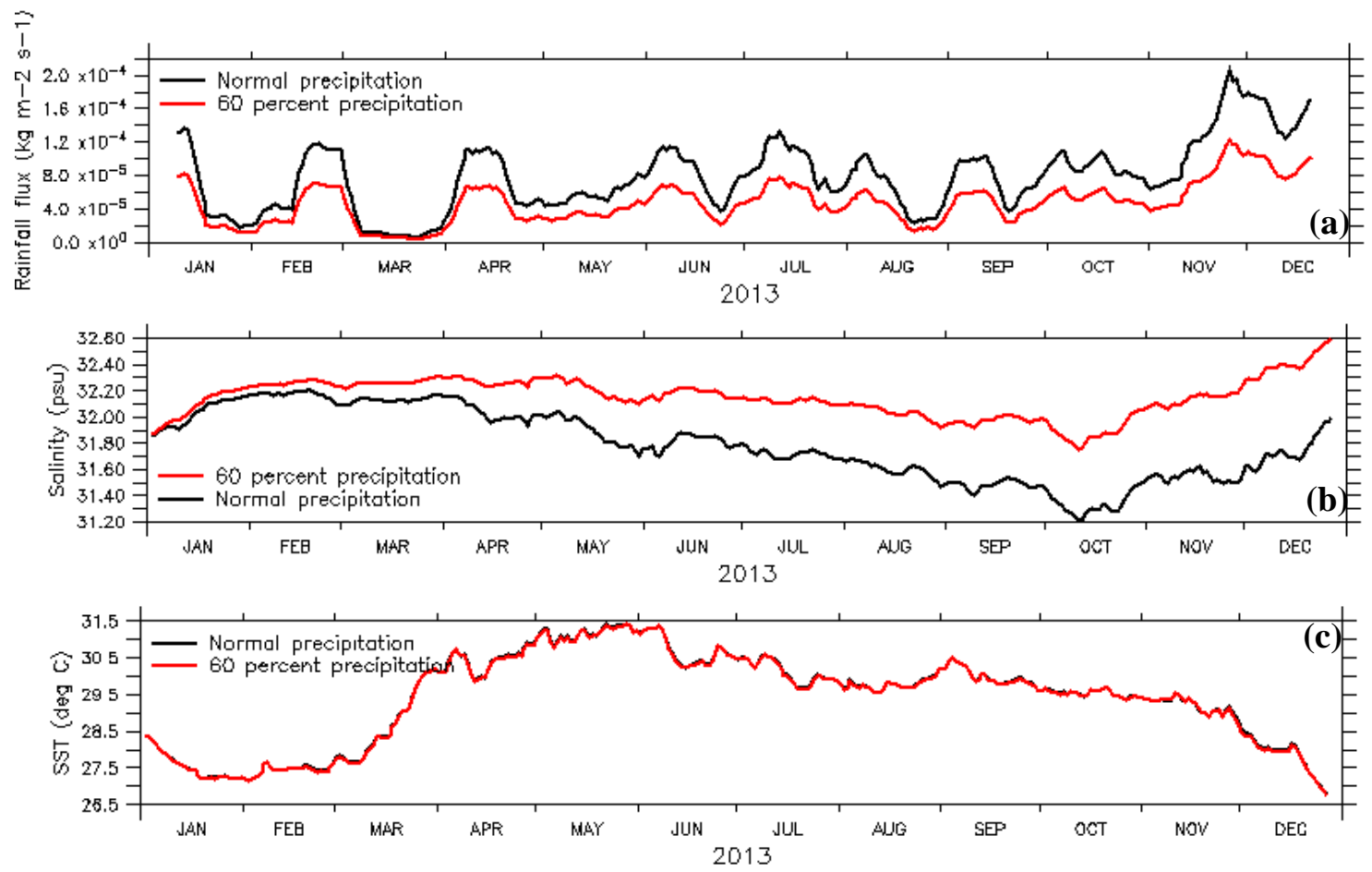

Figure 4. (a) Averaged of 15-day run-mean precipitation, (b) daily sea surface salinity, and (c) daily sea surface temperature on the South China Sea area. Black line indicates normal precipitation and red line indicates $60 \%$ precipitation simulated model. 
The SSS differences of two simulations are not vary too much after two months simulation in the Java Sea (Figure 5) and the Banda Sea (Figure 6). Annual average of SSS in Java Sea for operational run and 60\% precipitation are $31.06 \pm 0.72$ psu and $31.50 \pm$ 0.74 psu respectively. There is a difference of
$0.44 \pm 0.17$ psu between them. In the Banda Sea annual average of SSS for both simulations are $33.75 \pm 0.25 \mathrm{psu}$ and $34.04 \pm 0.24 \mathrm{psu}$ in which operational run simulation provides fresher waters. The annual difference of SSS in this area is $0.29 \pm 0.10 \mathrm{psu}$.
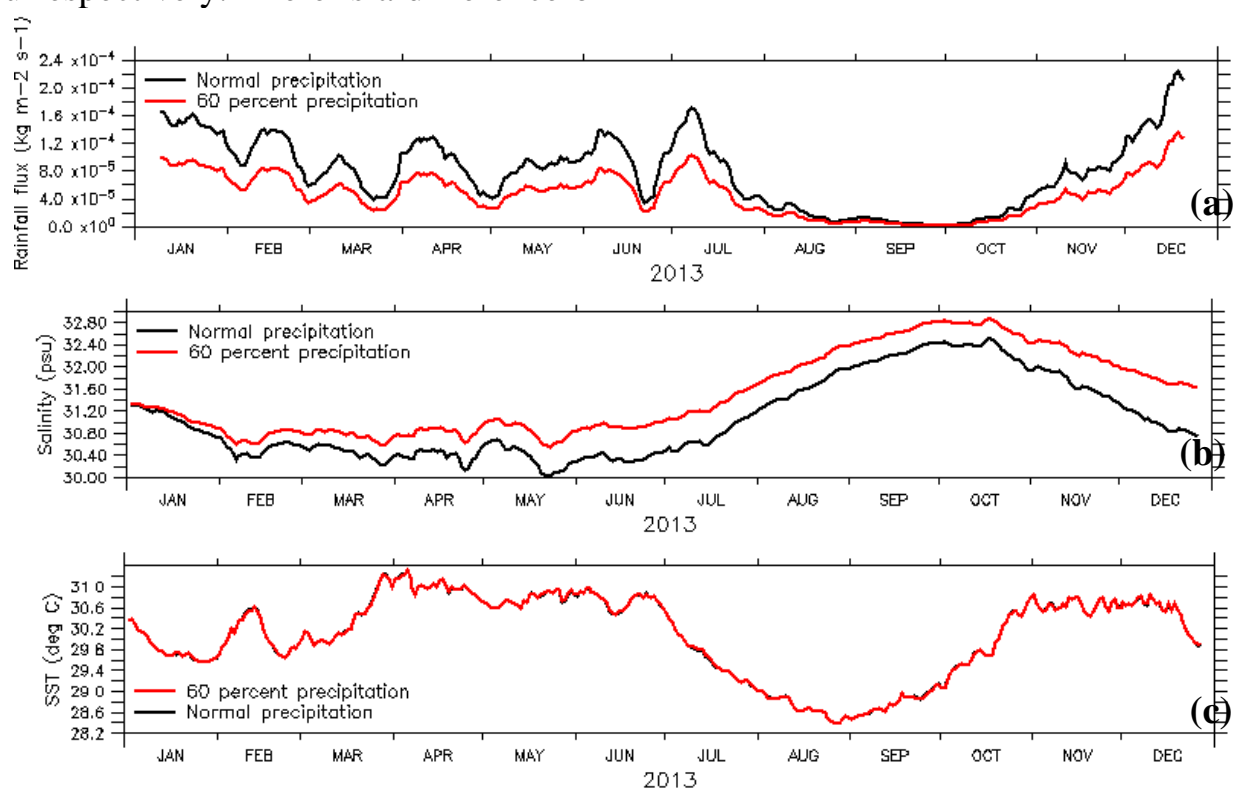

Figure 5. (a) Averaged of 15-day run-mean precipitation, (b) daily sea surface salinity, and (c) daily sea surface temperature on the Java Sea area. Black line indicates normal precipitation and red line indicates $60 \%$ precipitation simulated model.
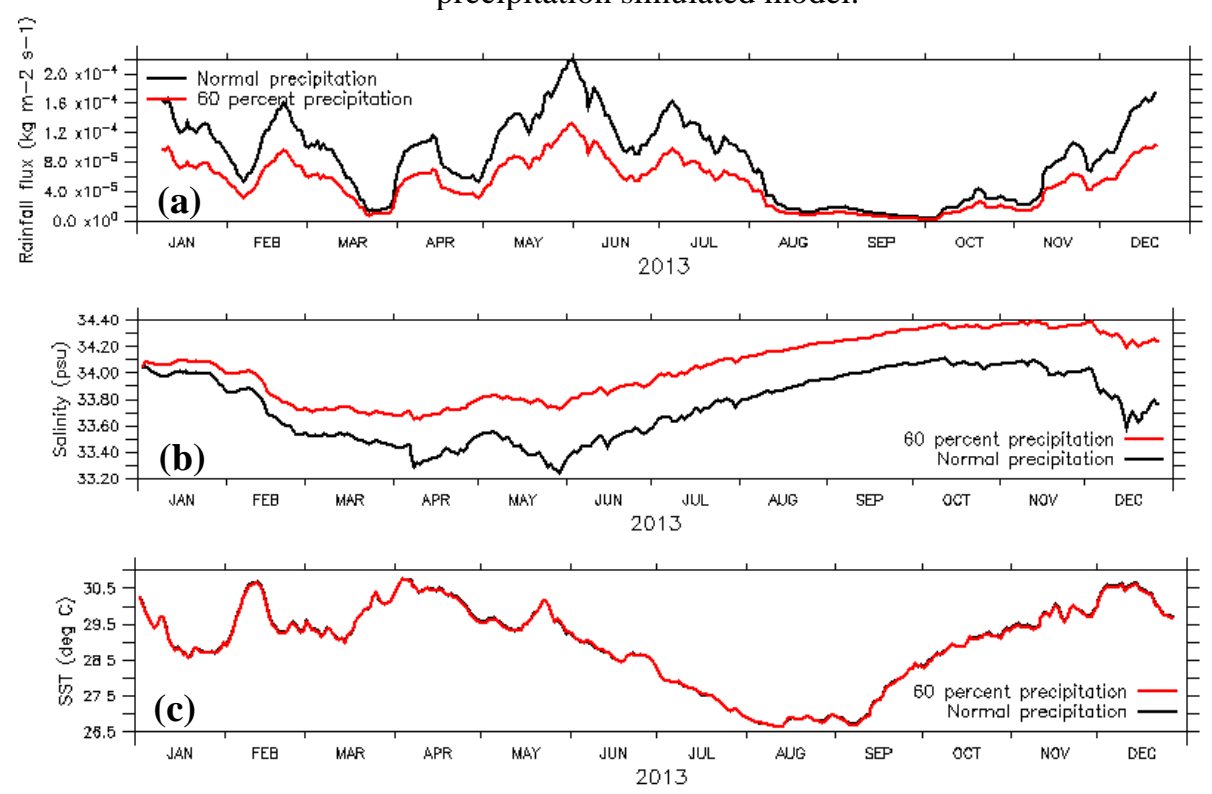

Figure 6. (a) Averaged of 15-day run-mean precipitation, (b) daily sea surface salinity, and (c) daily sea surface temperature on the Banda Sea area. Black line indicates normal precipitation and red line indicates $60 \%$ precipitation simulated model.

The SSS difference of two simulations is vary along the simulation in the Southern Java Sea area (Figure 7). Annual average of SSS in this area for operational run and $60 \%$ precipitation are $33.74 \pm 0.34$ psu and $33.99 \pm$ 
$0.28 \mathrm{psu}$ respectively. There is a difference of $0.26 \pm 0.12$ psu between two simulations.

Figure 8 shows the time series discrepancy of SSS and SST on the selected areas. The difference of SSS is obtained from subtraction of normal precipitation SSS by $60 \%$ precipitation SSS. The difference of SST is obtained from similar method.
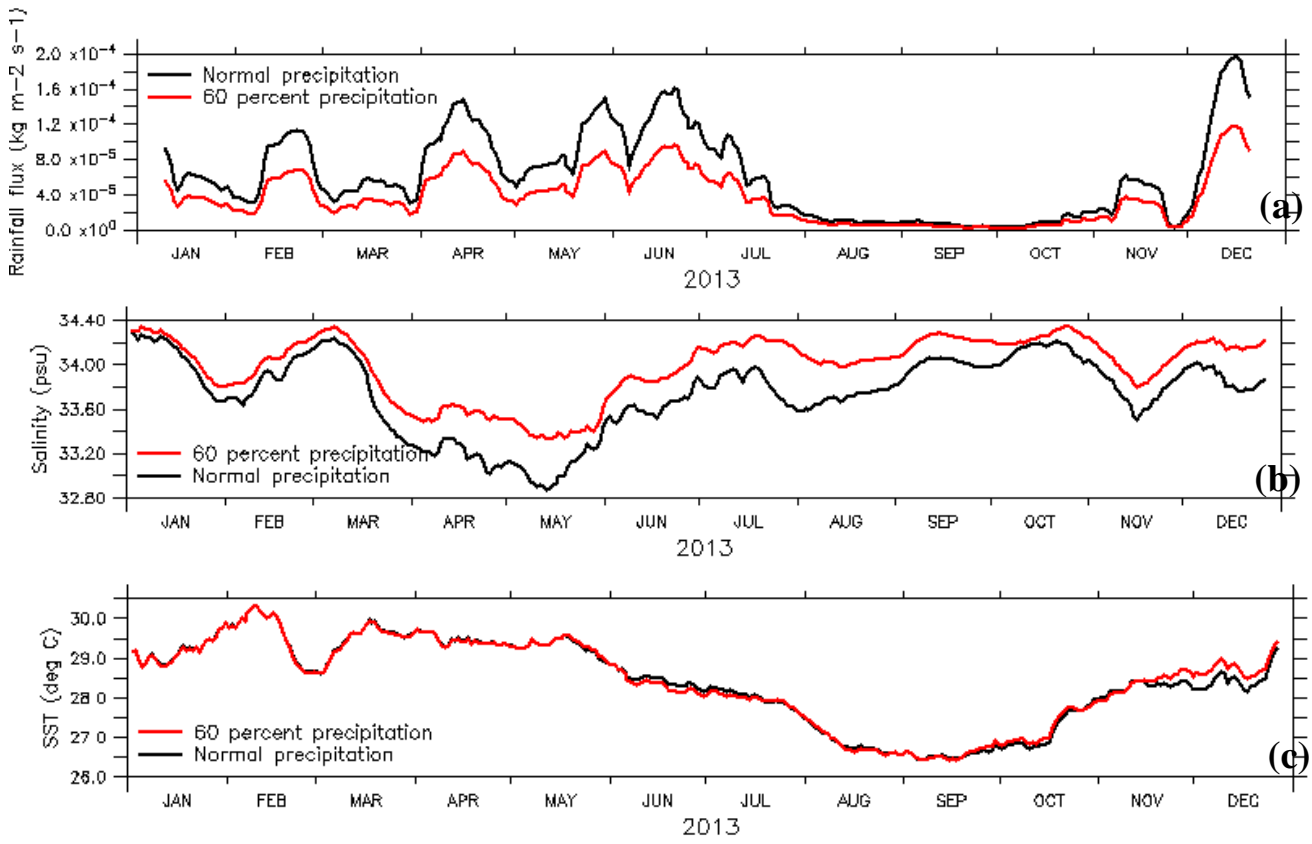

Figure 7. (a) Averaged of 15-day run-mean precipitation, (b) daily sea surface salinity, and (c) daily sea surface temperature on the Southern Java Sea area. Black line indicates normal precipitation and red line indicates $60 \%$ precipitation simulated model.
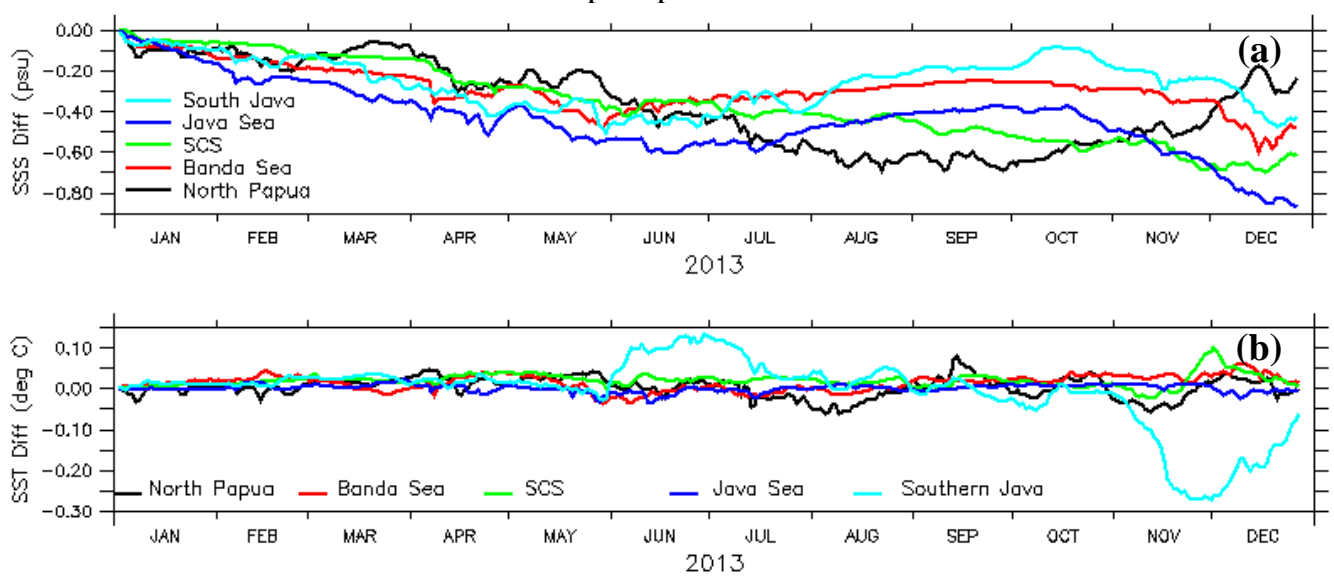

Figure 8. Daily discrepancies of SSS (a) and SST (b) in the selected area. The difference obtains by operational run simulation minus $60 \%$ precipitation simulation.

Table 1. The summary of annual SSS and SST as well as its difference from test case 1

\begin{tabular}{|l|lll|lll|}
\hline \multicolumn{1}{|c|}{ Selected area } & \multicolumn{3}{|c|}{ SSS (psu) } & \multicolumn{3}{c|}{ SST (deg C) } \\
& $100 \%$ prec. & $6 \% \%$ prec. & Difference & $100 \%$ prec. & $60 \%$ prec. & Difference \\
\hline Northern Papua waters & $33.79 \pm 0.22$ & $34.16 \pm 0.13$ & $0.37 \pm 0.20$ & $30.15 \pm 0.27$ & $30.15 \pm 0.26$ & $0.00 \pm 0.02$ \\
Banda Sea & $33.75 \pm 0.25$ & $34.04 \pm 0.24$ & $0.29 \pm 0.10$ & $28.97 \pm 1.17$ & $28.96 \pm 1.16$ & $0.01 \pm 0.02$ \\
South China Sea & $31.79 \pm 0.27$ & $32.15 \pm 0.15$ & $0.36 \pm 0.19$ & $29.41 \pm 1.25$ & $29.39 \pm 1.24$ & $0.02 \pm 0.02$ \\
Java Sea & $31.06 \pm 0.72$ & $31.50 \pm 0.74$ & $0.44 \pm 0.17$ & $30.07 \pm 0.78$ & $30.07 \pm 0.78$ & $0.00 \pm 0.01$ \\
Southern Java waters & $33.74 \pm 0.34$ & $33.99 \pm 0.28$ & $0.26 \pm 0.12$ & $28.47 \pm 1.16$ & $28.47 \pm 1.16$ & $0.00 \pm 0.08$ \\
\hline
\end{tabular}

The $40 \%$ reduction of precipitation affects the sea surface salinity by an increase in the entire model domain (Figure 9). The magnitude of SSS increase varies for different 
specific areas. This may be caused by the distribution of precipitation rate is not same in all areas. Figure 9 shows distribution of annual average SSS difference in the entire model domain. For Indonesian waters domain, the $40 \%$ reduction of precipitation will affect 0.35 \pm 0.13 psu SSS increase for annual average.

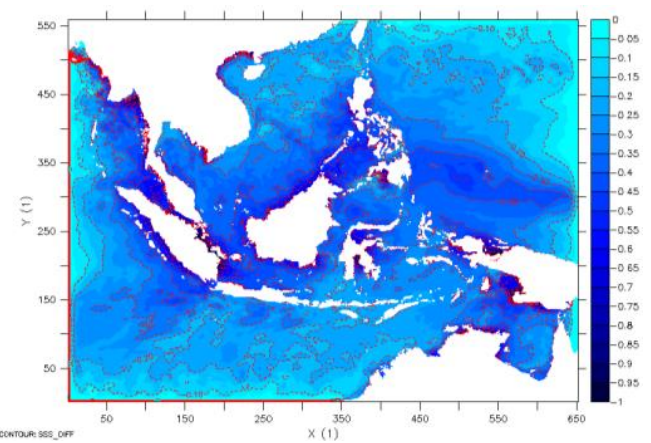

Figure 9. Distribution of annual average SSS difference in the entire INDO12 model domain (psu unit). The difference obtains by operational run simulation minus $60 \%$ precipitation simulation.

The reduction of precipitation seems to have no significant effects on the SST. Overlaid plot of averaged two simulated SST shows that both of them are the same almost all the time for all selected area (see subplot (c) in Fig. 3 - Fig. 7). Fig. 8(b) shows that the difference of SST is close to zero for all the time, except for the Southern Java waters. There are looks like seasonal/semi-annual signal appear in time series of Southern Java waters SST discrepancy. It seems the reduction of precipitation will reinforce the upwelling and downwelling phenomena in the Southern Java waters.

In the NEMO model, the prognostic equations of the two active tracers (potential temperature and salinity) can be summarized as follows, see [1]:

$$
\begin{aligned}
N X T= & A D V+L D F+Z D F+ \\
& S B C+(+Q S R)+(+B B C)+ \\
& (+B B L)+(+D M P)
\end{aligned}
$$

where $N X T$ denotes the time level of $n+1$. The term right hand side of (1) are the advection $(A D V)$, the lateral diffusion $(L D F)$, the vertical diffusion $(Z D F)$, the contributions of the external forcings $(S B C$ : surface boundary condition, $Q S R$ : penetrative solar radiation, and $B B C$ : bottom boundary condition), the contribution of the bottom boundary layer $(B B L)$ parameterization, and an internal damping $(D M P)$ term.

The precipitation is contained in $S B C$ term as an external forcing. Including the evaporation and river runoff, precipitation is used in the freshwater budget variable, represented by EMP (evaporation minus precipitation minus river runoff) in the model calculation. As EMP is used directly in the forcing terms for salinity then the difference of precipitation is directly effect on calculated salinity. The temperature of precipitation is not well known. In the model, it is assumed that this water has the same temperature as the sea surface temperature. Calculation of temperature is more affected by nonpenetrative part of the net surface heat flux (difference between the total surface heat flux and the fraction of the short-wave flux that penetrates into the water column) than precipitation. Precipitation rate will have an indirect concentration/dilution effect on temperature by Bulk formulae. This explains why the calculated temperature is not sensitive to precipitation changes.

\section{Effect on salinity profiles}

A comparison of salinity vertical profiles from two simulations is shown. Five representative areas are used (see previous part) in this analysis. Spatial and time average is performed to get one single vertical salinity profile for each selected area. Figure 10 shows the comparison and the differences between two simulations in different selected areas.

Precipitation changes are not only affected on surface salinity. In Fig. 10 (f) we can see that the salinity difference is appeared until $200 \mathrm{~m}$ depth in the Banda Sea. Indeed, the effect is not same for all area. The effect of precipitation on the subsurface salinity depends on the vertical mixing and the mean circulation (advection), that is vary in the entire domain. The area with the strongest mixing has the deepest influence on the salinity profile, even if the sea surface salinity changes are not too large. The differences of sea surface salinity in Northern Papua waters and South China Sea are larger than in Banda Sea, but the effect on the stratification in Banda Sea is stronger. 

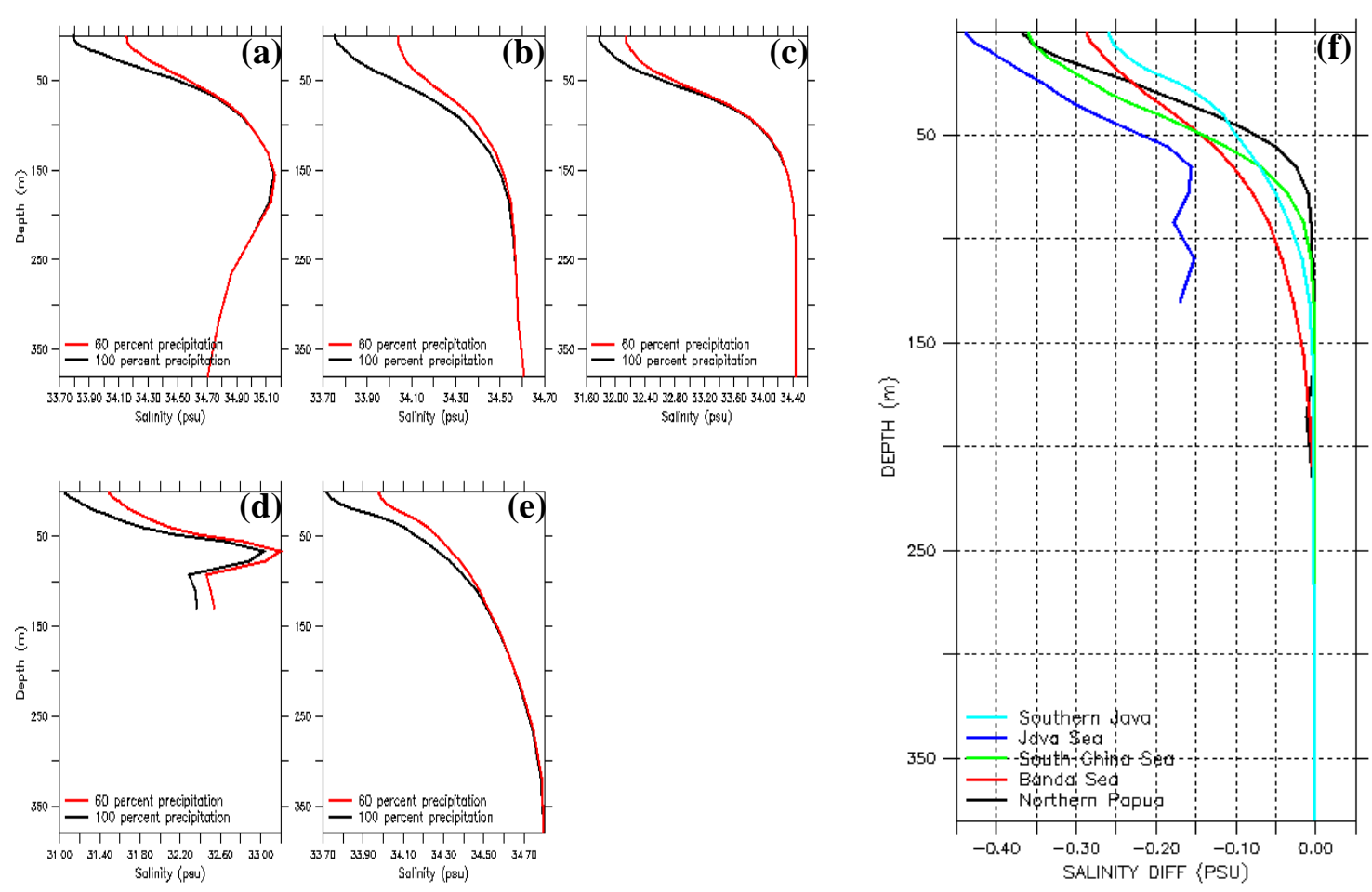

Figure 10. Salinity profile comparison for (a) Northern Papua waters, (b) Banda Sea, (c) South China Sea, (d) Java Sea, and (e) Southern Java waters. The profile is derived from area and annual time average. (f) The difference of salinity profile for each selected area, calculated by operational model minus $60 \%$ precipitation model.

\section{Fresh water budget}

The change of fresh water flux directly affects the model's salinity. Figure 11 shows time series of total fresh water budget in the precipitation and runoff reduction area. The negative values mean that there is fresh water flux into the ocean, and conversely for a positive. In the Fig. 11 we can see that both the precipitation and runoff reduction have an impact on the reduction of fresh water budget into the ocean. Compared with runoff reduction, the precipitation reduction has a larger effect in the total of fresh water budget.

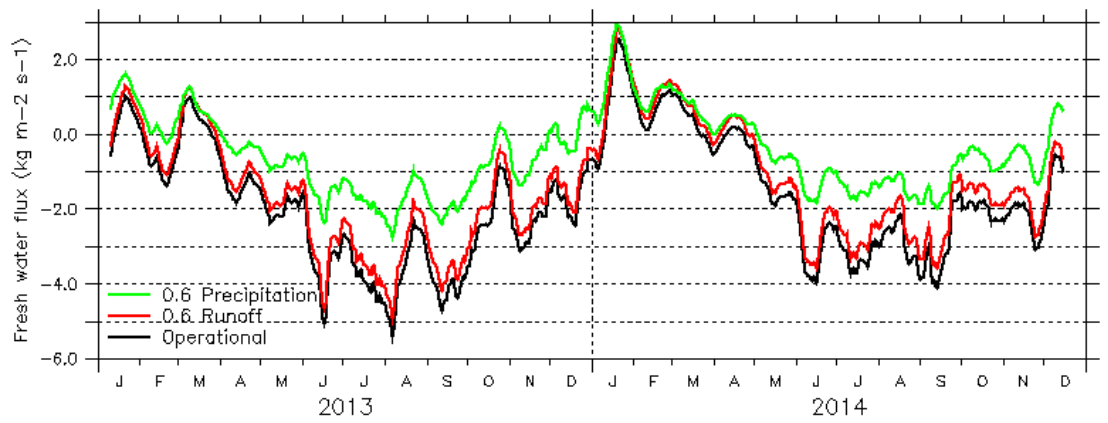

Figure 11. A 15 -days run-mean of the total fresh water budget in the $2^{\circ} \mathrm{S}-25^{\circ} \mathrm{N}$ and $100^{\circ} \mathrm{E}-120^{\circ} \mathrm{E}$ area. Black line indicates the operational model, red line indicates the $60 \%$ precipitation run, and green line indicates the $60 \%$ runoff run.

The total fresh water budget averages in the reduction area are $-1.77 \pm 2.06 \mathrm{~kg} \mathrm{~m}^{-2} \mathrm{~s}^{-1}$, $0.47 \pm 1.35 \mathrm{~kg} \mathrm{~m}^{-2} \mathrm{~s}^{-1}$, and $-1.39 \pm 2.00 \mathrm{~kg} \mathrm{~m}^{-2}$ $\mathrm{s}^{-1}$ for operational model, $40 \%$ precipitation reduction model, and $40 \%$ runoff reduction model respectively. In the study area, the reduction of $40 \%$ precipitation induces a reduction of approximately $39.7 \%$ for the total fresh water budget whereas the $40 \%$ runoff 
reduction induces a reduction of $8.6 \%$ during 2013-2014 simulation times.

\section{Sea surface salinity}

Both the precipitation and runoff reduction have an impact on the increase of sea surface salinity. The salinity change induced by the precipitation reduction is larger than that which would have been induced by the same percentage of runoff reduction. Fig. 12 shows the time series of sea surface salinity averaged in the South China Sea area, the Karimata Strait area and the Java Sea area for two years simulation. The salinity increase in the Java Sea area is smaller than in the others area. It is because the Java Sea is outside of the precipitation or runoff reduction area. The salinity changes in the Java Sea come from an indirect effect of the precipitation or runoff changes, where is applied in the South China Sea area. The increase of salinity in the reduction area affects the peripheral salinity, include the Java Sea, by the advection and diffusion processes.
The salinity changes in the Java Sea area starting to look stable in the second-year simulation time. It seems to take about one year simulation to spread out the salinity change induces by precipitation or runoff reduction in the South China Sea to the Java Sea area.

Table 2 shows the annual mean of sea surface salinity from operational model, $60 \%$ precipitation model, and $60 \%$ runoff model, as well as its difference. The annual mean is calculated from second year of simulation assuming the model has been in a stable state. The number in the table shows that $40 \%$ reduction of precipitation in the South China Sea area induces the salinity increase approximately $0.72 \pm 0.14 \mathrm{psu}, 0.74 \pm 0.15 \mathrm{psu}$, and $0.44 \pm 0.11$ psu in the South China Sea, Karimata Strait, and Java Sea area respectively. These values are larger than the salinity increase induces by reduction of runoff which produces the changes approximately $0.22 \pm$ $0.10 \mathrm{psu}, 0.24 \pm 0.09 \mathrm{psu}$ and $0.13 \pm 0.03 \mathrm{psu}$ in the same area.
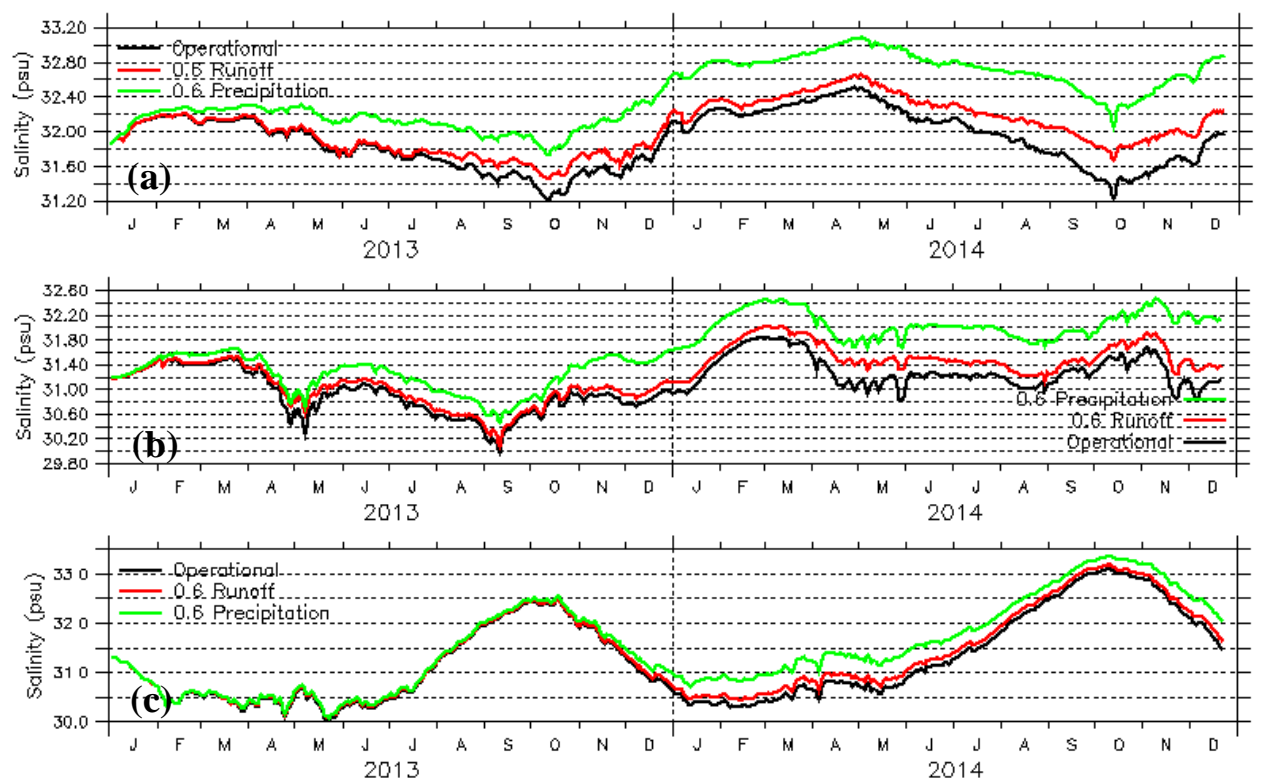

Figure 12. Time series of sea surface salinity averaged in the South China Sea (a), Karimata Strait (b), and Java Sea (c). Black line indicates operational model, red line indicates $60 \%$ runoff run, and green line indicates $60 \%$ precipitation run. 
Table 2. The annual mean of sea surface salinity from operational model, $60 \%$ precipitation model, $60 \%$ runoff model, and its difference*

\begin{tabular}{|l|c|c|c|c|c|}
\hline \multirow{2}{*}{ Area } & \multirow{2}{*}{$\begin{array}{c}\text { Operational } \\
\text { model SSS }\end{array}$} & \multicolumn{2}{|c|}{$\mathbf{6 0 \%}$ runoff model } & \multicolumn{2}{c|}{$\mathbf{6 0 \% \text { precipitation model }}$} \\
\cline { 3 - 6 } & SSS & $\begin{array}{c}\text { Diff to } \\
\text { operational }\end{array}$ & SSS & $\begin{array}{c}\text { Diff to } \\
\text { operational }\end{array}$ \\
\hline South China Sea & $32.00 \pm 0.32$ & $32.22 \pm 0.23$ & $-0.22 \pm 0.10$ & $32.72 \pm 0.21$ & $-0.72 \pm 0.14$ \\
\hline Karimata Strait & $31.30 \pm 0.26$ & $31.53 \pm 0.23$ & $-0.24 \pm 0.09$ & $32.04 \pm 0.22$ & $-0.74 \pm 0.15$ \\
\hline Java Sea & $31.47 \pm 0.95$ & $31.60 \pm 0.93$ & $-0.13 \pm 0.03$ & $31.91 \pm 0.86$ & $-0.44 \pm 0.11$ \\
\hline
\end{tabular}

*The differences are calculated by operational model salinity minus modified model salinity. The negative sign means the salinity of modified model is larger than operational

The distribution of salinity changes is different between the $60 \%$ precipitation simulation and the $60 \%$ runoff simulation. The salinity change in the $60 \%$ runoff model is more localized in the coastal area. It is quite obvious because the runoff reduction takes places near the coast. Both of modified simulations show that the salinity changes are concentrated in the concern area, even after one year simulation time. Figure 13 shows an annual mean of salinity changes distributions from second year simulation.

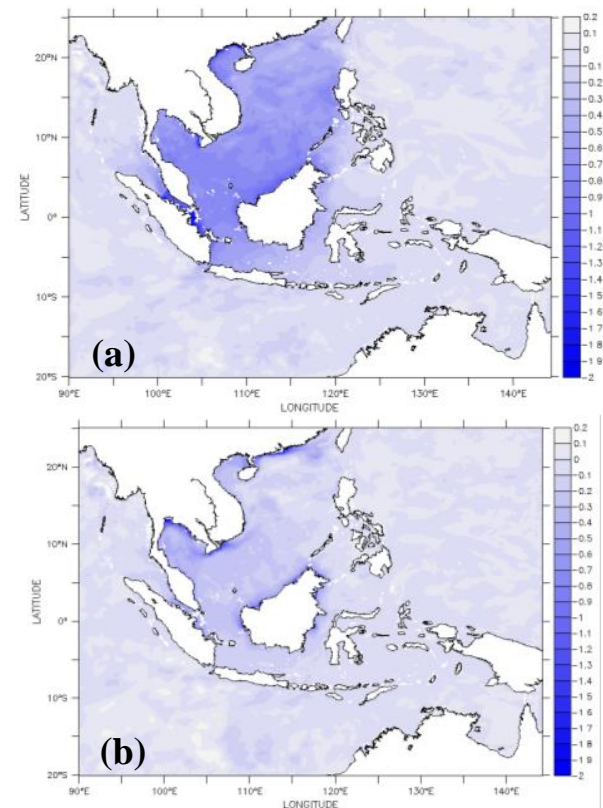

Figure 13. (a) The sea surface salinity annual mean differences between the operational simulation and the precipitation reduction simulation. (b) The salinity annual mean differences between the operational simulation and the runoff reduction simulation.

\section{Mixed layer depth (MLD)}

The mixed layer depth (MLD) can be defined by the vertical profile of temperature and the turbocline depth. Turbocline depth is the depth at which the vertical eddy diffusivity coefficient (resulting from the vertical physics) fall below a given value defined locally (here taken equal to $5 \mathrm{~cm} / \mathrm{s} 2$ ). Figure 14 shows both of the MLD calculated by operational model, $60 \%$ precipitation run, and $60 \%$ runoff run. Since the South China Sea is the only area that the MLD is defined, in the Karimata Strait and Java Sea MLD is not defined due to shallow depth, the comparison of MLD from three simulations is performed only in this area. The MLD defined by sigma theta (vertical profile temperature) is shallower than turbocline depth, but both of them have similar trend.

In Fig. 14 we can see that the MLD at South China Sea area is not change too much due to the changes of precipitation or runoff. It seems the sea surface salinity changes is not much affected to physics vertical gradient. Even the sea surface salinity is changed in the precipitation or runoff reduction, the gradient in depth of the value is almost similar to operational model. The 2014 annual mean of turbocline MLD in the South China Sea for operational model, $60 \%$ precipitation run, and $60 \%$ runoff run is $15.90 \pm 9.05 \mathrm{~m}, 16.90 \pm 9.65$ $\mathrm{m}$, and $16.29 \pm 9.17 \mathrm{~m}$ respectively. There is a difference around $1.00 \pm 0.75 \mathrm{~m}$ between operational model and $60 \%$ precipitation run as well as $0.39 \pm 0.26 \mathrm{~m}$ between operational model and $60 \%$ runoff run. Both modified simulations produce shallower MLD than operational model. Almost same values of shallower MLD also shown in the annual mean of MLD defined by sigma theta. 

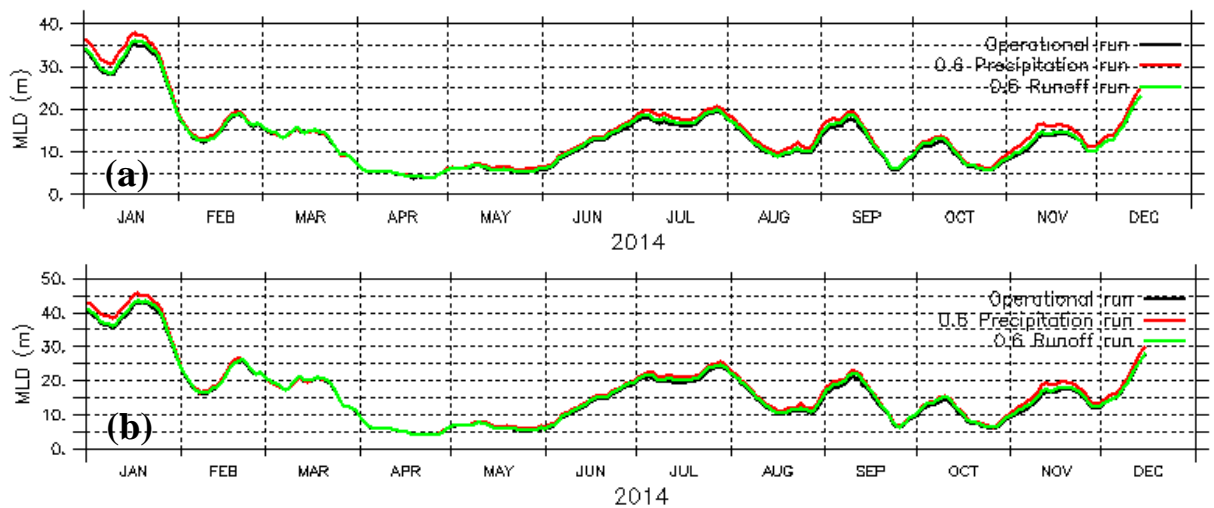

Figure 14. Comparison of mixed layer depth defined by sigma theta (a) and turbocline (b) calculated from operational model (black line), 60\% precipitation run (red line), and 60\% runoff run (green line).

\section{CONCLUSION}

Sensitivity test cases of INDO12 model to precipitation and runoff modification were evaluated in this study. It is shown that the reduction of precipitation or runoff induces salinity increase, in which the effect of precipitation reduction is larger than runoff reduction for the same percentage. Although both of precipitation and runoff processes takes place on the surface, the changes of them would affect subsurface salinity stratification. Comparison of precipitation and runoff induced salinity changes with operational model salinity indicates that $40 \%$ reduction of precipitation and runoff explained $2.0 \%$ and $0.6 \%$ of the changes in salinity within South China Sea to Java Sea area.

Different effect is seen for temperatures variable. The assumption that used in the INDO12 model makes the precipitation or runoff change have not significant effect to sea water temperature. As a consequence, the mixed layer depth defined by temperature stratification is almost similar between the operational and modified model. This result indicates that variability in precipitation and runoff may not be critical variables to simulation of temperature in the INDO12 model.

Performing a useful tool of sensitivity analysis on our study is an effective way to further understand the dynamics, it can help to explain the behaviour seen within the model as well by understanding its response to changes in precipitation and runoff parameter changes. The value of the model parameters is shown especially how they can be used to calibrate the model to achieve a more accurate simulation.

\section{ACKNOWLEDGEMENT}

We thank Benoit Tranchant and Nathalie Verbrugge for their supervision on this study. The work was also supported by the INDESO program.

\section{REFERENCES}

[1] Z. Di, Q. Duan, W. Gong et al., "Parametric sensitivity analysis of precipitation and temperature based on multi-uncertainty quantification methods in the Weather Research and Forecasting model," Sci. China Earth Sci. vol. 60, no. 5, pp. 876-898, Mar 2017. https://doi.org/10.1007/s11430-0169021-6

[2] G. R. Halliwell Jr., L. K. Shay, J. K. Brewster, and W. J. Teague, "Evaluation and Sensitivity Analysis of an Ocean Model Response to Hurricane Ivan," Monthly Weather Review, vol. 139, no. 3, pp. 921-945, Mar 2011. https://doi.org/10.1175/2010MWR3104. 1

[3] M. D. Mateus and G. Franz, "Sensitivity Analysis in a Complex Marine Ecological Model," Water, vol. 7, no. 12, pp. 2060-2081, May 2015. https://doi.org/10.3390/w7052060 
[4] F. Pianosi, K. Beven, J. Freer, J. W. Hall, J. Rougier, D. B. Stephenson, and T. Wagener, "Sensitivity analysis of environmental models: A systematic review with practical workflow," Environmental Modelling \& Software, vol. 79, pp. 214-232, Feb 2016. https://doi.org/10.1016/j.envsoft.201 6.02 .008

[5] F. Ferretti, A. Saltelli, and S. Tarantola, "Trends in sensitivity analysis practice in the last decade," Science of the Total Environment, vol. 568, pp. 666-670, Mar 2016.

http://dx.doi.org/10.1016/j.scitotenv.201 6.02 .133

[6] M. Rodrigues, A. Oliveira, M. Costa, A. B. Fortunato, and Y. Zhang, "Sensitivity Analysis of an Ecological Model applied to the Ria de Aveiro," Journal of Coastal Research, Special Issue 56 (Proceedings of the $10^{\text {th }}$ International Coastal Symposium), pp. 448-452, 2009.

[7] J. G. Kim, E. C. Hunke, and W. H. Lipscomb, "Sensitivity analysis and parameter tuning scheme for global seaice modelling," Ocean Modelling, vol. 14, pp. 61-80, May 2006. doi:10.1016/j.ocemod.2006.03.003

[8] Y. Shi, W. Gong, Q. Duan, J. Charles, C. Xiao, and H. Wang, "How parameter specification of an Earth system model of intermediate complexity influences its climate simulations," Prog. Earth Planet Sci, vol. 6, no. 46, Jun 2019. https://doi.org/10.1186/s40645-0190294-x

[9] G. Madec and NEMO System Team, "NEMO Ocean Engine - version3.1," Scientific Notes of Climate Modelling Center (27), Institute Pierre-Simon Laplace (IPSL), France, 300pp, ISSN No. 1288-1619, 2008.

[10] B. Tranchant, G. Reffray, E. Grenier, D. Nugroho, A. Koch-Larrouy, and P. Gaspar, "Evaluation of an operational ocean model configuration at $1 / 12^{\circ}$ spatial resolution for the Indonesian seas (NEMO2.3/INDO12) - Part 1: Ocean physics," Geosci. Model Dev., vol. 9, pp. 1037-1064, Mar 2016. https://doi.org/10.5194/gmd-9-10372016

[11] B. Priyono, M. Trenggono, and T. Agustiadi, "Validation of INDO12 Ocean Model at Makassar Strait," Journal of Fisheries and Marine Research, vol. 16, no. 2, pp. 83-89, Dec 2020.

http://dx.doi.org/10.20884/1.oa.2020.16. 2.663

[12] M. Trenggono, B. Priyono, R. R. Hidayat, and T. Agustiadi, "Comparison of Simulated and Observed Current Velocities in Karimata and Gaspar Straits," Journal of Fisheries and Marine Research, vol. 16, no. 3, pp. 42-48, Dec 2020. http://dx.doi.org/10.20884/1.oa.2020.16. 3.853 